\title{
Los cráneos trofeo Condorhuasi-Alamito (Catamarca, Argentina) dentro del pensamiento religioso andino
}

\author{
Jimena Roldán y María Marta SAmpietro Vattuone \\ Instituto Miguel Lillo, Universidad Nacional de Tucumán - CONICET \\ jimena_roldan@yahoo.com sampietro@tucbbs.com.ar
}

Recibido: 5 de abril de 2010

Aceptado: 26 de marzo de 2011

\section{RESUMEN}

En la región del Campo del Pucará (Catamarca, Argentina) se localiza un centro ceremonial que perteneció a la cultura formativa Condorhuasi, denominado Condorhuasi-Alamito. En él se manufacturaban objetos suntuarios y se oficiaban rituales donde se practicaba el sacrificio y posterior desmembramiento de seres humanos. Como resultado de ello, cada parte del cuerpo se resignificaba: algunas piezas se enterraban o se descartaban en basureros ceremoniales y otras, como los cráneos, recibían un trato especial y se transformaban en «cráneos o cabezas trofeo». La forma de obtención de esos cráneos y el constante uso de los mismos en tiempo y espacio donde lo que cambiaba era el significado que se les adscribía, son características que las culturas del NOA comparten con culturas de otras regiones de los Andes centrosur.

Palabras clave: Religión, Andes centro-sur, Condorhuasi-Alamito, cráneos trofeo.

\section{Condorhuasi-Alamito Trophy Heads (Catamarca, Argentina) in the Andean Religious Thinking}

\begin{abstract}
In the region called «Campo del Pucará (Catamarca, Argentina)» where was located a ceremonial place which belonged to the Condorhuasi Formative culture, under the name of Condorhuasi-Alamito, sanctuary objects were manufactured and rituals were celebrated where human beings sacrifices and subsequent bodies dismembered were common practices. As a result of, each part of the body were resignified, some parts of it were buried or disposal as ceremonial trash, and others like heads received a special treatment and were transformed into «trophy heads or skulls». The way in which they were obtained, as well as the constant use of them, in time and space, where what changed was the meaning ascribed to it. Those are characteristics aspects that the NOA cultures shared with other cultures in southcentral Andean regions.
\end{abstract}

Key words: Religion, South-Central Andean area, Condorhuasi-Alamito, trophy heads.

Sumario: 1. Introducción 2. Marco conceptual 3. Religiosidad Andina (cráneos trofeo) 4. La religión en el Noroeste Argentino 5. Discusión 6. Conclusiones 7. Referencias bibliográficas.

\section{Introducción}

Intentar explicar situaciones rituales prehispánicas a partir de la evidencia material dejada por sus usuarios no es tarea fácil. El pensamiento religioso de estos pueblos es sumamente complejo y requiere de una cantidad importante y variada de evidencias 
físicas que permita interpretarlo contextualmente. Por otra parte, existe una disrupción en la evolución de estas prácticas introducida por la imposición del catolicismo durante el período de conquista y colonización española.

Las culturas prehispánicas involucradas en este trabajo concreto, se estudian a partir de los restos materiales encontrados, no tienen continuidad histórica actual ni estuvieron en contacto con los primeros colonizadores europeos, por lo tanto no hay documentación escrita de las mismas. Además, una de las limitaciones más importantes viene dada por la diferencia entre la forma en que nosotros (como occidentales de fuerte influencia cristiana) entendemos el mundo que nos rodea y como estos pueblos antiguos entendían el suyo. Intentar interpretar su forma de pensamiento a través del nuestro exige superar siglos de historia y cambios sociales que derivaron en lo que somos actualmente. A pesar de ello, hacer inferencias de tipo ideológico a partir de restos físicos no es una tarea imposible.

Se cree que en el territorio andino existen rasgos de un pensamiento religioso común a todos los grupos culturales prehispánicos que habitaron la región, plasmado en el arte cerámico, lítico, textil, rupestre, etc.

La diferencia se apoya en la consistencia, variabilidad y temporalidad del registro arqueológico para cada zona. En el caso del Noroeste Argentino (NOA) el hallazgo de cráneos trofeo en contextos ceremoniales u otros, junto con la parafernalia que acompaña a la actividad ritual en la cual están insertos, es particularmente escaso y por lo tanto su interpretación es muy escueta, no ocurriendo lo mismo en la región de los Andes Centrales (principalmente en territorio peruano). En este contexto se consi-

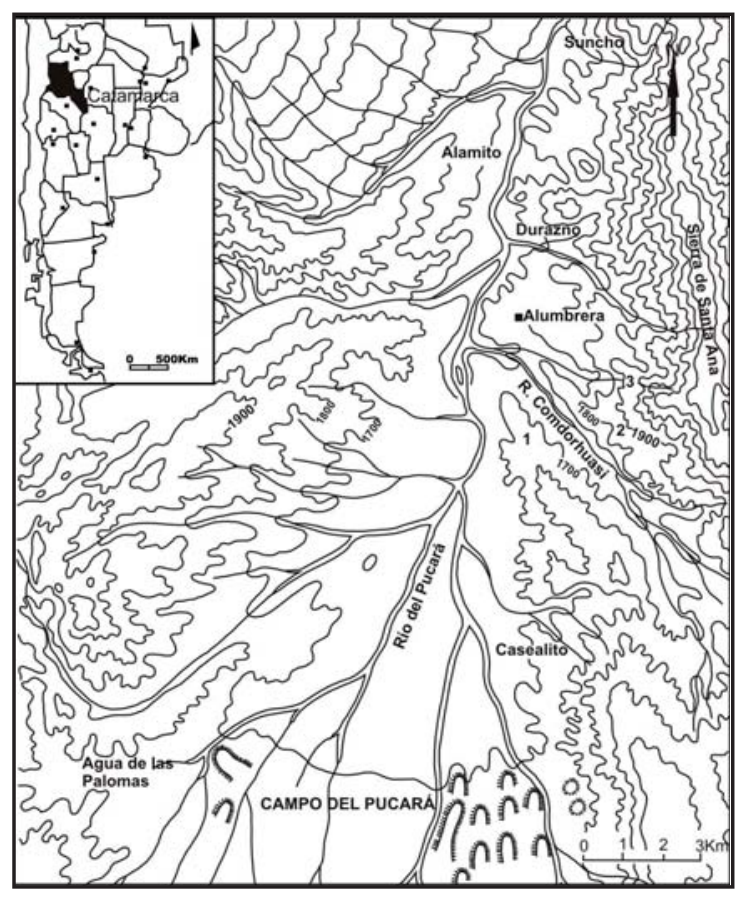

Figura 1: Mapa de ubicación de los sitios arqueológicos Condorhuasi-Alamito (Campo del Pucará, Catamarca, Argentina). Tomado de Núñez Regueiro 1998. 
dera que los trabajos realizados sobre el particular en la región peruana son altamente significativos a la hora de interpretar nuestros datos, teniendo siempre en cuenta las diferencias culturales, espaciales y temporales que existen entre aquellas culturas y la cultura Condorhuasi-Alamito, objeto del presente estudio.

Los sitios Condorhuasi-Alamito componen el primer centro ceremonial descrito para el Formativo en la región del NOA (Figura 1). Cada uno de ellos presenta un plano de simetría que los divide en dos mitades, una ocupando el sector norte del sitio y otra el sur. Cada mitad está compuesta por una plataforma, un cobertizo, talleres y habitaciones, que reflejan una estructura dual en la organización de la arquitectura y por lo tanto del grupo social. El montículo mayor, las plataformas, los recintos C (o cobertizos) y los recintos A (o talleres) integran lo que podemos considerar el área ceremonial, a la que habría que sumarle el patio central. Por otro lado, en oposición a esta área, se ubican los recintos $\mathrm{B}$ (o habitaciones) que componen un número reducido dentro de cada sitio, sólo de 2 a 6 por sitio. Los recintos restantes son menores en tamaño y altura, y constituyen lo que se ha definido como talleres o talleres metalúrgicos por el tipo de evidencia arqueológica encontrada en ellos (Figura 2) (Tartusi y Núñez Regueiro 2001).

Dentro de este marco, el objetivo de este trabajo es mostrar cómo se insertan los cráneos trofeos en el contexto ritual de los sitios ceremoniales de Condorhuasi-Alamito, hallados en Campo del Pucara (Catamarca, Argentina) y definir si forman parte de una concepción religiosa mayor, común a todos los pueblos andinos.

Figura 2: Croquis del sitio ceremonial 1-B encontrado en Campo del Pucará (Catamarca, Argentina). Tomado de Núñez Regueiro 1998.

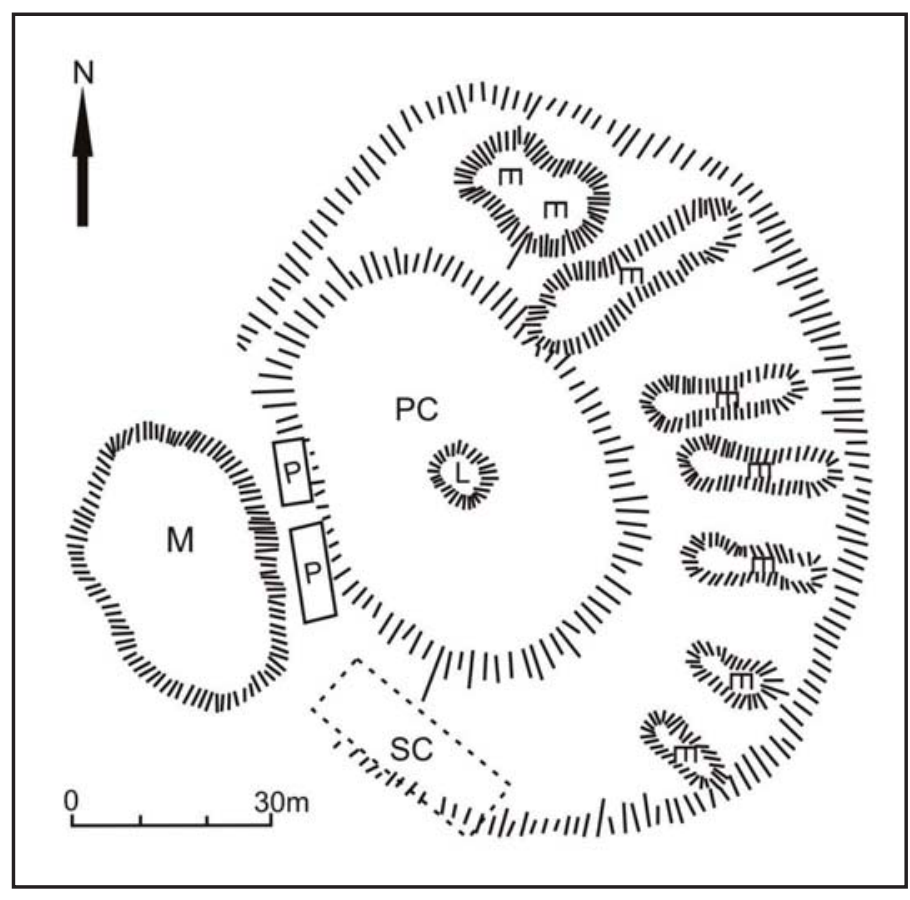




\section{Marco conceptual}

Como punto de partida es de fundamental importancia explicar qué se entiende por religión en arqueología. El concepto de religión está en permanente debate, pero coincidimos con Insoll (2004) cuando establece que cuanto más simple es la definición, mejor. En muchos aspectos, la religión es indefinible debido a que incluye lo intangible e irracional, pero también funciona dentro de un contexto lógico donde hay un sistema que se construye a través de antiguas tradiciones de pensamiento sobre los problemas humanos fundamentales (vida, muerte, dios, amor, etc.). Para la arqueología de la religión, los elementos sagrados comprometen no sólo la materia, sino también sus implicaciones materiales profundas, y pueden relacionar todas las dimensiones de la cultura material. Esta categoría se relaciona e interactúa con otras esferas de la vida y debe ser tenida en cuenta desde esa perspectiva.

El contexto arquitectónico general en el que se hallaron los cráneos trofeos, es definido como de tipo ceremonial. Estos centros eran una institución representada por un espacio socialmente organizado para desempeñar funciones cúlticas, que actuaron además como centros de administración y poder. En los mismos residían permanentemente los chamanes, que ofrecían determinados tipos de servicios a una colectividad dispersa o concentrada en poblados cercanos, la cual acudía periódica o eventualmente al centro. En una escala menor, estos centros estaban constituidos por estructuras ceremoniales, definidas como de tipo simple, ya sea el caso de un montículo; o compleja, como los denominados «complejos de plataformas en forma de U» (sitio de La Rinconada), cuyas características y elementos asociados permiten inferir su carácter ceremonial (Tartusi y Núñez Regueiro 2001).

Dentro de las actividades que se practicaban en estos centros se encuentra el ritual. Éste involucra tanto acción como actividad mental, es descrito como la posesión de emociones, experiencias, movimiento y comunicación, todos ellos combinados. El ritual puede ser tanto rutinario como excepcional; en el primer caso tiende a darse en lugares y tiempos específicos y su fin es mantener a largo plazo el efecto que el ritual provoca en las personas. En general es reconocido por su formalidad (De Marrais et al 1996, Insoll 2004, Rappaport 1971).

Se sabe que los rituales andinos de sacrificios, tanto humanos como animales, están relacionados directa o indirectamente con los ciclos agrícolas. La frecuencia y regularidad con la que se manifiesta este tipo de ceremonia se hace evidente con la aparición de sociedades agrícolas-ganaderas (González 1998, Tartusi y Núñez Regueiro 2001).

Este acto convierte al cuerpo en un objeto sagrado repleto de un significado institucionalizado. Este principio asume que las partes del cuerpo son una forma de cultura material que sufre cambios de significado a través de su vida de uso social (Hill 2003). El sacrifico permite que los vivos puedan acceder al mundo divino. Esta relación con lo sobrenatural ocurre por medio del cuerpo sacrificado. La muerte del individuo sirve como una forma de intercambio comunicativo en la cual los humanos proveen de una ofrenda y lo sobrenatural retribuye, proveyéndolos con buena salud y cosechas, ración adecuada de agua, etc. (Hill 2003). 
Cuando en los rituales de sacrificio o en actos de guerra se cercena la cabeza de un individuo y ésta recibe un trato especial para poder conservarla y ser utilizada como objeto de múltiples significados, podemos decir que la misma se transforma en un «cráneo o cabeza trofeo».

Para poder entender el comportamiento ritual en el que se utilizaron estos cráneos, es importante tener en cuenta que todo objeto ritual puede distinguirse por las diferentes actuaciones en las cuales participa durante estadios particulares de su vida, incluyendo la etapa final de descarte (Walker 1998), que en nuestro caso es una de las más significativas.

En esta última etapa, estos objetos singulares entran frecuentemente en el registro arqueológico como basura ceremonial descartada. Éstos pueden o no ser dañados intencionalmente en el momento de su descarte, a través del fuego o rotura y el lugar de desecho está asociado con espacios sagrados. El patrón consistente que presenta la basura ceremonial, independiente de las diferentes y a veces contradictorias creencias culturales, demuestra que el comportamiento ritual puede mantenerse como una unidad de análisis arqueológico (Walker 1995).

\section{Religiosidad andina (cráneos trofeo)}

En la región andina centro-sur (norte de Chile, Noroeste Argentino, cuenca del Titicaca y Perú) existió, en tiempos prehispánicos (desde el surgimiento de culturas agro-alfareras), un conjunto de rasgos religiosos comunes, pese a la enorme variedad de estilos, prácticas y culturas, representada por el complejo felínico y ceremonias rituales que incluían, entre otras, la decapitación y el desmembramiento de cuerpos humanos (Figura 3).

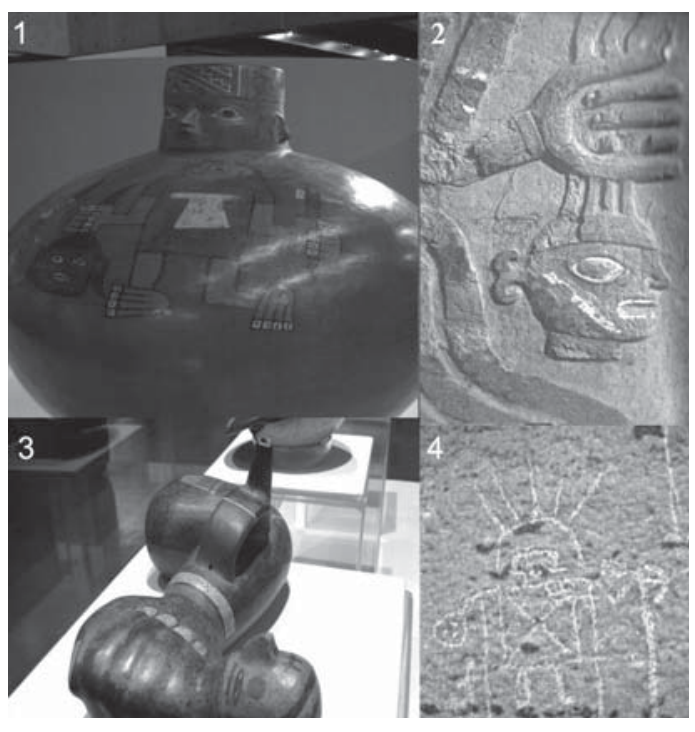

Figura 3: Representaciones de cabezas cercenadas en diferentes culturas de los Andes centro-sur: (1) cráneo trofeo huari; (2) cráneo trofeo moche; (3) cabeza trofeo nazca; (4) individuo sosteniendo una cabeza cercenada (Santa Bárbara, Chile); tomado de Nielsen 2007. 
Dentro de estas prácticas religiosas, el sacrificio humano acompañado por la extracción de cráneos para su utilización en dichas prácticas, tiene una larga historia, tanto en los Andes centrales, comenzando en el Período pre-Cerámico (1800 a.C.) y continuando a través del Período Inca (Proulx 2001), como en los Andes australes a partir del Período Formativo Temprano (300 a.C.) hasta la llegada del Inca (1500 d.C.) (González 1998, Nielsen y Walker 1999, Verano 2008). En este punto es importante tener en cuenta que en los últimos diez años se hallaron enterramientos precerámicos (5900-650 a.C. aproximadamente) aislados de cabezas cercenadas y un enterramiento de un cuerpo al que le falta el cráneo en la región puneña del Noroeste Argentino. Sin embargo los investigadores son reacios a hablar de cabezas trofeo en un época tan temprana y con poca evidencia material que lo respalde (Hernández Llosas 2000, López y Miranda 2007/08, Yacobaccio 2000, 2001).

La obtención de los cráneos trofeo se realizaba en el campo de batalla o a partir de rituales donde el chamán oficiaba de intermediario entre el mundo de los espíritus o sobrenatural y el mundo de los vivos o natural. Cuando el acto sacrificial era consumado, se entablaba una estrecha relación con lo divino a través del cuerpo sacrificado. Esto implica que el acto del sacrificio es un evento de transformación, donde la separación de la cabeza del cuerpo lleva a una resignificación de ambas partes. En el caso de los cráneos se transformaban en objetos sagrados imbuidos de significados distintos dentro de cada grupo social y entre grupos sociales diferentes. Para algunos contenía la esencia de un ser querido (veneración de los ancestros), para otros eran símbolos de poder o formaban parte de un todo con su universo religioso, no descartándose la posibilidad de simbolizar todas estas creencias a la vez (Browne, Silverman y García 1993; Hill 2003; Nielsen 2007; Proulx 1999, 2001; Verano 2008).

Las representaciones de cabezas trofeo pueden relacionarse tanto con el mundo sobrenatural y las hierofanías como con el prestigio social y la guerra; su integridad e importancia simbólica no varían, aún así la actividad de decapitar no fue estática a través del tiempo. Un claro ejemplo se da dentro de la cultura Nasca, donde en épocas tempranas la fuente de cabezas trofeo fue la actividad ceremonial, mientras que en el Período Tardío las mismas se obtenían como resultado de actos de guerra (Browne, Silverman y García 1993, Proulx 1999).

Las cabezas cercenadas y las ceremonias que las propiciaban estaban asociadas con ciclos de muerte y regeneración/renacimiento/fertilidad, su fin era el de asegurar la continuidad en la abundancia de alimentos producto del cultivo. Los cráneos trofeo eran sustitutos visuales y metafóricos de plantas o partes de plantas. En pocas palabras, los actos de violencia y sacrificios estaban vinculados con la práctica agrícola y la reciprocidad (Browne, Silverman y García 1993; De Leonardis 2000; Eliade 1964; González 1998; 2004; Proulx 1999, 2001; Swenson 2003). Es probable que esta ideología acompañara a los primeros cultígenos en su dispersión, explicando de esta manera la convergencia de ciertas prácticas en un territorio tan extenso como es el americano (González 1998). Los cráneos son personificados como fuentes de vida, y en algunos casos se representan con plantas emergiendo de sus cavidades (De Leonardis 2000). 
Más allá del uso individual que cualquier cráneo trofeo pudo tener, una vez terminada su vida útil, muchos eran ritualmente enterrados en grupos (Proulx 2001). El descarte de los mismos pudo obedecer a la muerte de su usuario o simplemente a que se volvieron obsoletos; de cualquier manera se convierten en basura ceremonial y el lugar donde fueron enterrados tiende a ser sagrado (Walker 1995).

Dentro del contexto social en el cual se oficiaban estas ceremonias ocurrían importantes cambios que llevarían a reformular el comportamiento religioso de los pueblos andinos.

El desarrollo de un culto jerárquico organizado provocó el traslado de la actividad ritual de un contexto habitacional a uno de carácter público (Figura 4). El acceso a los recursos rituales se encontraba limitado por las reglas impuestas por un pequeño grupo de personas que también controlaban la circulación y el acceso a los objetos ceremoniales. La construcción de sitios dedicados exclusivamente a la actividad religiosa es parte de este sistema de centralización, donde la escenografía arquitectónica fue utilizada para reafirmar y legitimar la autoridad y el poder que los líderes poseían (Browne, Silverman y García 1993; Tartusi y Núñez Regueiro 2001; Walker y Lucero 2000). De esta manera comienza a manifestarse la desigualdad social reflejada en la centralización de la actividad religiosa, la cual va acompañada de ceremonias

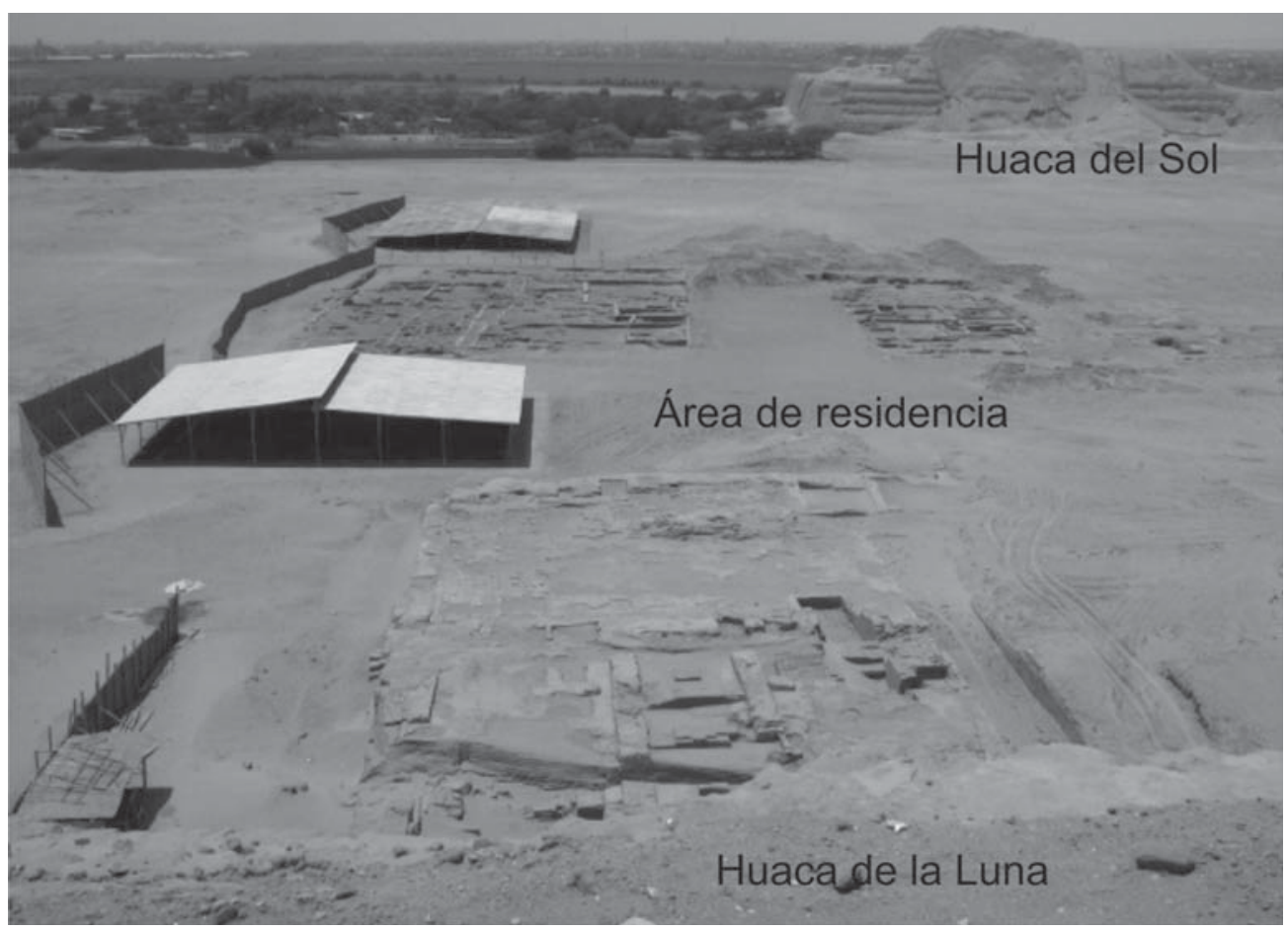

Figura 4: Fotografía actual de una estructura ceremonial moche; en la Huaca de la Luna se practicaban los sacrificios humanos. 
que involucran el sacrifico humano (González 1998, Nielsen 1995, Núñez Regueiro 1998, Swenson 2003).

En los Andes meridionales y australes, el Período Tardío, específicamente desde el siglo XIII hasta la formación del Tahuantinsuyo en el siglo XV, fue una época de conflictos endémicos importantes que Nielsen (2007) denomina como período de guerra evidenciado en la presencia de sistemas defensivos, armas, rastros osteológicos de violencia e iconografía.

\section{La religión en el Noroeste Argentino}

El fenómeno religioso que se desarrolló en el Noroeste Argentino en tiempos prehispánicos fue complejo y supuso una larga evolución histórica. Como se planteó con anterioridad, su ideología no era muy diferente a la observada en el resto del territorio andino. González (2004) señala que la presencia de muchos rasgos políticos-religiosos en las culturas del Período Formativo del NOA (Tafí, Condorhuasi y Ciénaga) provienen de la influencia recibida de grupos culturales PrePukara y Pukara de la región de la cuenca del Titicaca, los cuales a su vez recibieron influencias provenientes de culturas localizadas en la región andina central (Perú). Como resultado de ello se desarrollan culturas como Aguada en el NOA y Tiahuanacu en Bolivia que comparten elementos comunes y temas similares o idénticos como el personaje de los dos cetros, el sacrificador, el sacrificador con máscara felínica, etc. (González 2004).

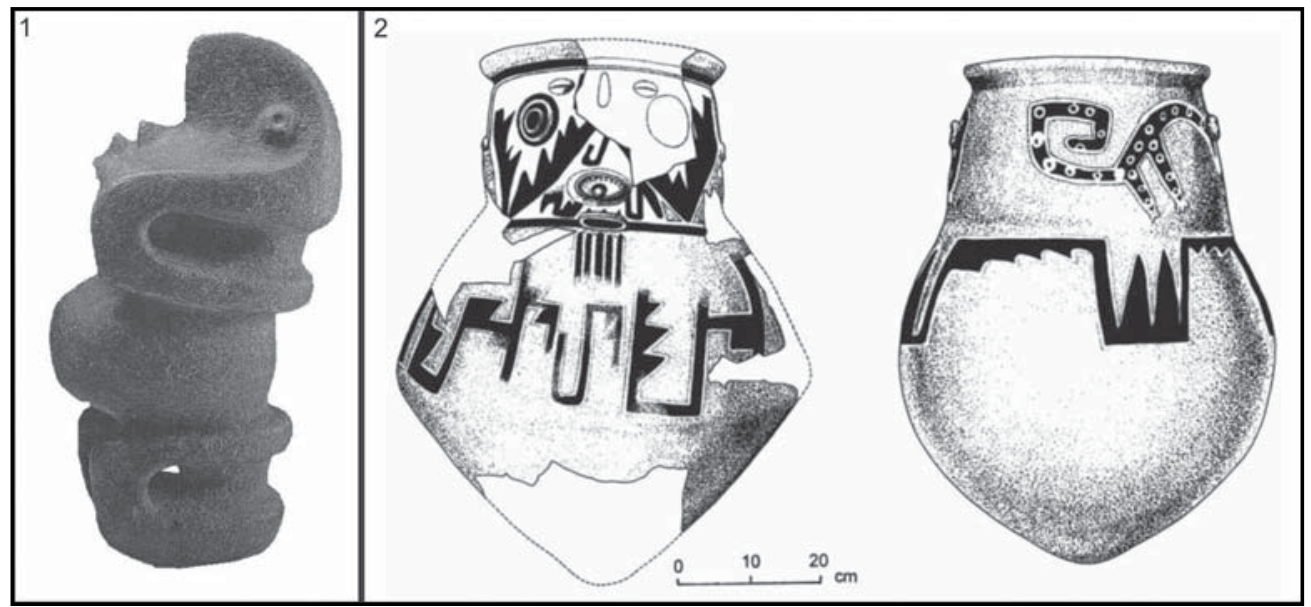

Figura 5: Algunos objetos arqueológicos pertenecientes a Condorhuasi-Alamito encontrados en Campo del Pucará (Catamarca, Argentina): (1) suplicante de piedra, tomado de Tartusi y Núñez Regueiro 2001; (2) vasija Alumbrera tricolor, tomado de Núñez Regueiro 1998. 
En esta región se cree que existieron dos tradiciones bien definidas e importantes que se relacionaban y complementaban. Por un lado, el culto a los muertos, quienes eran venerados y jugaban un papel activo en el mundo de los vivos, y por otro, el culto al felino, que en su momento de máximo esplendor estaba compuesto de hierofanías complejas y muy relacionadas con la actividad agrícola-ganadera (Tartusi y Núñez Regueiro 2001).

Las primeras manifestaciones de estos cultos se vieron en la alfarería Vaquerías (200 a.C.-200 d.C.), considerada parte de la cultura Condorhuasi. En su cerámica quedaron plasmadas representaciones de sacrificios humanos con cabezas cercenadas (pintadas sobre la cerámica o en forma de efigies) y posiblemente la utilización de alucinógenos (González y Baldini 1989, González 1998, 2004, Núñez Regueiro y Tartusi 2002, Tartusi y Núñez Regueiro 1993).

Sin embargo, los indicadores más tangibles de un culto organizado se observaron recién en Condorhuasi-Alamito (240-500 d.C.) durante el Período Formativo. En la región de Campo del Pucará se encontró evidencia material de sitios arqueológicos utilizados como centros ceremoniales. La disposición espacial de sus estructuras y los objetos materiales encontrados dan cuenta de un grupo reducido de personas por sitio, cuyo trabajo fue el de manufacturar artefactos suntuarios de gran apreciación artística en cerámica, piedra y metal, y oficiar rituales ceremoniales (Tartusi y Núñez Regueiro 1993) (Figura 5).

La arquitectura de cada sitio refleja la forma en que estos grupos entendían el mundo que los rodeaba. Cada uno de ellos puede ser dividido en dos partes iguales, y cada sección incluye estructuras dedicadas a la actividad sagrada (plataformas y recintos A y C) y otras pertenecientes al ámbito profano (recintos B) (Tartusi y Núñez Regueiro 1993) (ver Figura 2).

El registro cerámico informa sobre la pertenencia de estos sitios a la cultura Condorhuasi, pero debido a las actividades allí desarrolladas (manufactura de objetos suntuarios por parte de artesanos especializados y oficio de actividades religiosas) fueron considerados como la manifestación cúltica de dicha cultura, denominándolos entonces Condorhuasi-Alamito (Tartusi y Núñez Regueiro 1993).

Los rituales eran oficiados por chamanes, si bien el personaje del sacrificador, que podría ser identificado con el del chamán, se manifiesta claramente en el Período Medio con la cultura Aguada, pero sus orígenes están en los sitios CondorhuasiAlamito. En estas ceremonias se utilizaban alucinógenos (la presencia de tabletas de rapé y pipas es muy frecuente en Condorhuasi), cráneos trofeo y se practicaban sacrificios, tanto humanos como animales (Núñez Regueiro y Tartusi 2002). En estos sitios la existencia de «cráneos trofeo» está respaldada por el hallazgo de: tallas cefalomorfas, en las proximidades de las plataformas, que se cree estuvieron empotradas en las paredes; un recipiente con decoración negra pintada sobre fondo crema de una cabeza triangular con los pelos encrespados que pudo representar una cabeza cercenada sostenida por el cabello; un aerófono pintado hecho con una tibia humana en el suelo de una estructura taller; cinco cráneos sobre el piso perfectamente conservados, dispuestos de tal manera que formaban una pirámide, posiblemente envueltos en algún tipo de tejido o dentro de un recipiente hecho de un material perecedero, encon- 


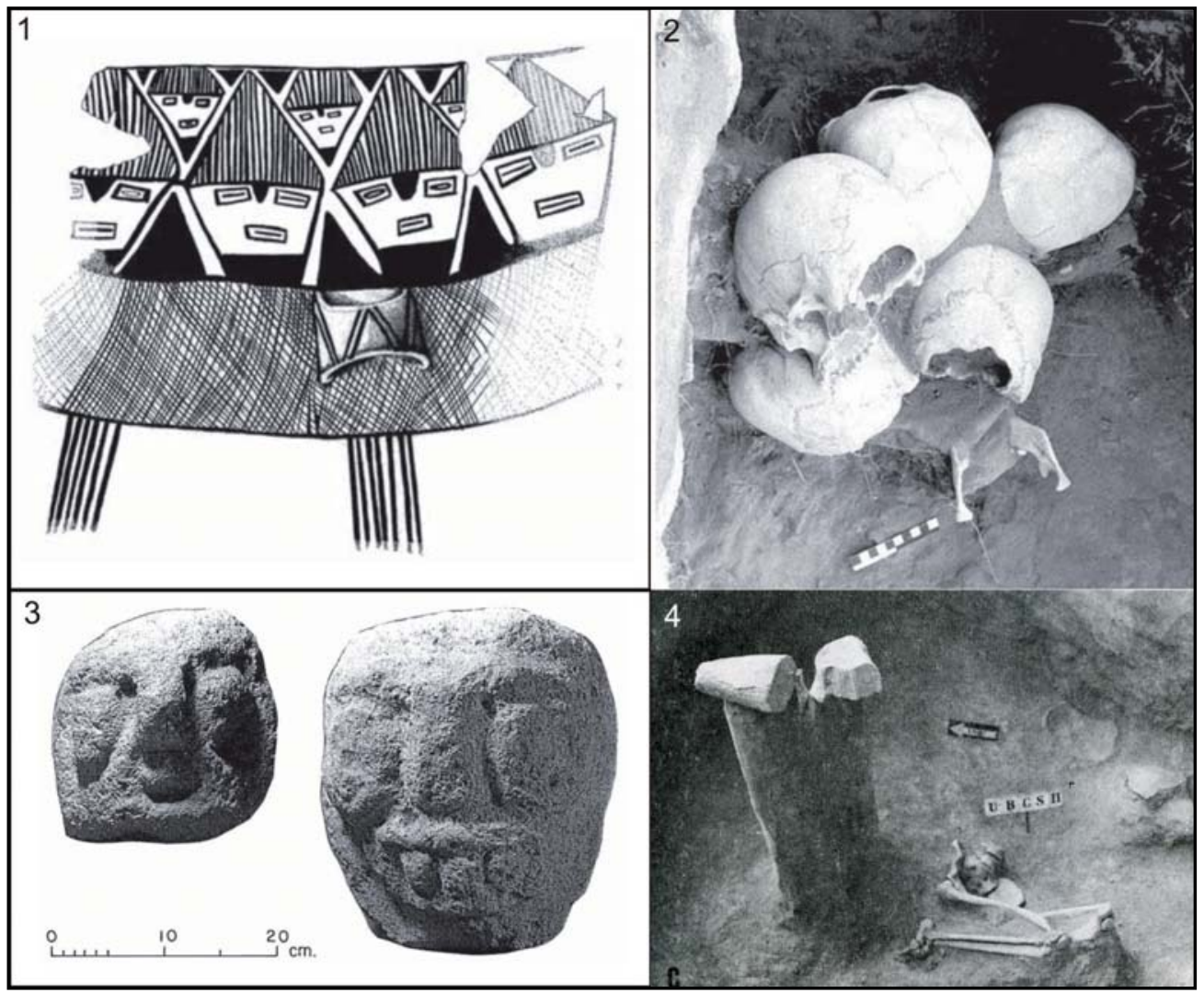

Figura 6: Material arqueológico encontrado en Campo del Pucará (Catamarca, Argentina) que muestra la existencia de sacrificios y desmembramiento de cuerpos humanos: (1) representaciones de cabezas cercenadas sobre una vasija; (2) fotografía de los 5 cráneos trofeo en la posición en que fueron encontrados; (3) cabezas de piedra; (4) Individuo al que le falta la mitad superior del cuerpo, estando el resto teñido de rojo. (1 a 3: tomado de Núñez Regueiro y Tartusi 2002; 4: tomado de Núñez Regueiro 1998).

trados en las proximidades de la estructura taller ya mencionada; una delgada hacha de cobre que podría haber sido utilizada para sacrificios; un individuo enterrado por debajo del piso de ocupación de un recinto habitacional al que le falta el tronco desde la zona lumbar hacia arriba, incluyendo el cráneo, mientras que el resto había sido pintado con pintura de color rojo; y restos óseos animales y humanos, adultos y niños, fragmentados, quemados y esparcidos en los pisos de los sitios y en la estratigrafía de los montículos ceremoniales (Núñez Regueiro 1998, Núñez Regueiro y Tartusi 2002) (Figura 6).

Estas actividades, junto con la parafernalia ritual, formaban parte del culto a la deidad solar, representada por el felino y plasmada en el arte cerámico y lítico (González 1998, Tartusi y Núñez Regueiro 1993, 2001). 
Estos sitios fueron lugar de encuentro y dispersión de ideas y objetos varios. El tráfico caravanero fue el medio utilizado para dicho fin. Los rituales y eventos desarrollados en ellos se utilizaron para afianzar lazos de solidaridad entre diferentes grupos (González 1998; Tartusi y Núñez Regueiro 1993, 2001).

La máxima expresión simbólico-religiosa andina en el NOA se da en el Período Medio (700-1100 d.C.) dentro de la cultura Aguada, que se manifiesta en la riqueza de imágenes religiosas plasmadas en todas las superficies de los objetos conocidos: cerámica, madera, hueso, lítica, metal, tejidos, etc., incluido el arte rupestre (Figura 7), el consumo de alucinógenos en todas sus formas posibles, y en los complejos arquitectónicos de carácter ceremonial que requirieron construcciones de mayor envergadura que la observada en el Campo del Pucará (González 1998; Pérez Gollán 2000; Tartusi y Núñez Regueiro 1993, 2001).

Para este momento, el imaginario religioso y su vínculo con culturas provenientes de la cuenca del Titicaca, norte de Chile y los Andes centrales, se encuentra claramente representado en placas de bronce fabricadas en el NOA donde están plasmados la deidad solar, el felino, el personaje de los dos cetros, el sacrificador y el personaje

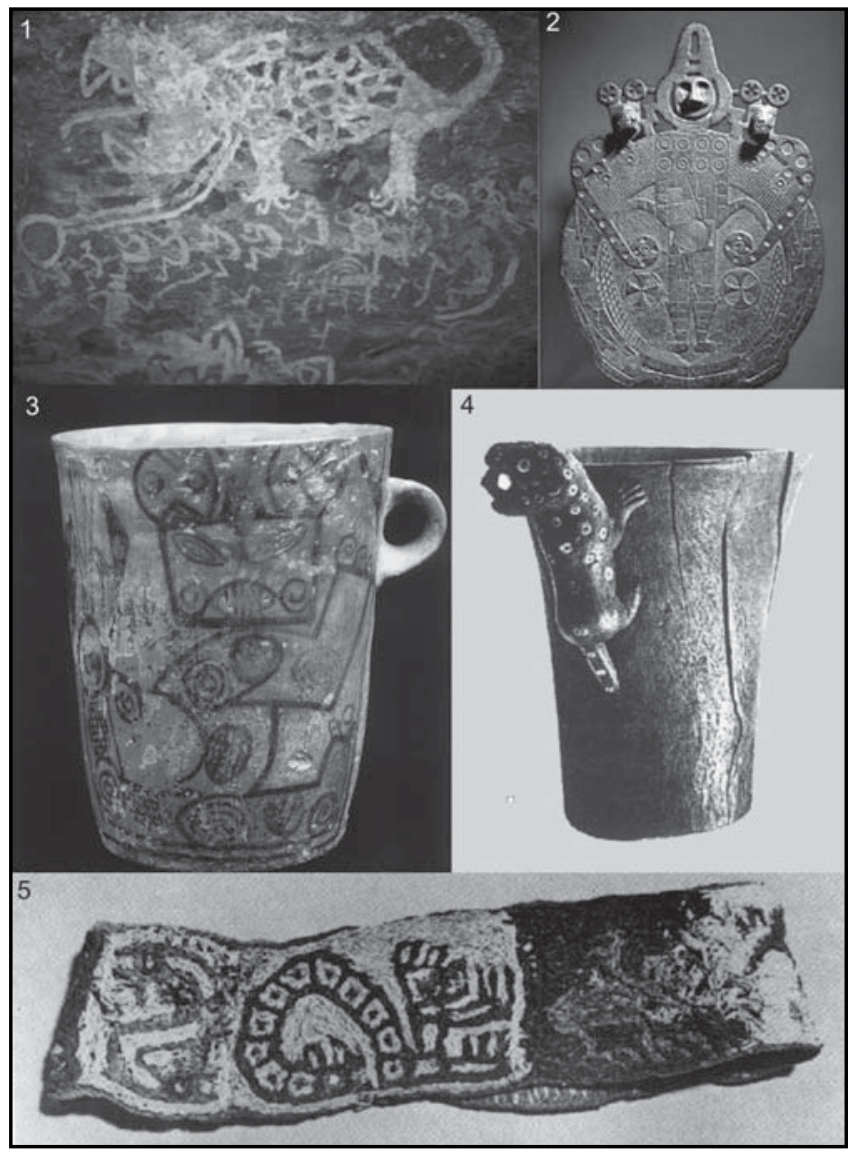

Figura 7: Objetos de diferentes materias primas pertenecientes a la cultura Aguada: (1) pictografía de la cueva La Salamanca donde se observa a un gran felino; (2) disco de bronce; (3) vaso de cerámica; (4) vaso de madera; (5) vincha de tela encontrada en San Pedro de Atacama. Tomados de González 1998. 
de las manos vacías, junto con otras imágenes zoomorfas (felinos, llamas, saurios, etc.). En ellas es posible reconocer una antigua religión andina cuyo eje era el culto al Punchao o deidad solar (González 2004, Pérez Gollán 2000).

Los cráneos trofeo son personificados como vasos de cabezas efigies, plasmados en la cerámica, solos o sostenidos por el personaje del sacrificador. La evidencia directa, es decir restos óseos humanos, se presenta en una variedad de comportamientos y prácticas mortuorias. En el centro ceremonial de La Rinconada (valle de Ambato, Catamarca) y en sitios asociados ubicados en el mismo valle, se encuentran restos óseos humanos dentro del relleno sedimentario; expuestos al calor y con huellas de manipulación intencional asociados a materiales de uso doméstico (exclusivamente cráneos en La Rinconada) encontrados sobre el piso de ocupación; entierros de partes humanas o individuos completos acompañados o no de restos de camélidos y entierros de infantes con y sin ajuar, todos ellos ubicados por debajo del piso de ocupación de recintos habitacionales, siendo algunos de tipo primario y otros secundarios. Si bien la información obtenida es escasa, es probable que en estos sitios se practicara el sacrificio humano, el cercenamiento de cráneos y su conservación como reliquias, y la antropofagia (Gordillo y Solari 2009).

La información que surge del registro arqueológico, a partir de los centros ceremoniales, aldeas y obras agrícolas, hablan de un orden ideológico, político y económico que hace pensar en la existencia de señoríos cuyo origen ya se vislumbraba en el Formativo con el complejo Condorhuasi-Alamito (Pérez Gollán 2000).

En el Período Tardío o de Desarrollos Regionales (1000-1450 d.C.) se observa una reestructuración social, producto de conflictos endémicos o guerras y posiblemente de cambios climáticos drásticos que derivaron en importantes sequías en gran parte de los Andes centrales (Thompson et al. 1985) y meridionales (Lupo 1998; Sampietro Vattuone 2002), que afectó a la forma de explotación agrícola y pastoril, la movilización de poblaciones, los circuitos de circulación de bienes, la arquitectura pública y las formas de cultura material (p. ej. los ritos funerarios). Todo lo cual revela el surgimiento de sociedades diferentes a sus antecesoras (Nielsen 2007).

Como resultado de ello, algunas representaciones cúlticas, propias de períodos anteriores, sobreviven en este período pero sufren una evidente resignificación (Nielsen 2007). En este sentido se pueden mencionar las placas tardías que eran utilizadas como parte de la vestimenta cuyo repertorio iconográfico está compuesto de cabezas cercenadas, serpientes, guerreros, etc.; también se hallan representaciones de estos guerreros y sus vestimentas en la cerámica santamariana (González 1979, Nastri 2008) (Figura 8). Para esta época las placas y la iconografía plasmada en ellas parecen estar relacionadas con la guerra y el estatus social del guerrero. Probablemente la obtención de cráneos trofeo permitía a los mismos controlar el poder del enemigo o servía como protección contra fuerzas asociadas que pudieran continuar amenazándolos (Vignati 1930), y conmemoraba sus logros en combate para alcanzar reconocimiento social (Verano 1995). Estos nuevos atributos no necesariamente desplazaban el significado religioso de los cráneos trofeo, pero evidentemente éste pasa a un segundo plano de significación. Evidencia de ello se encuentra en sitios arqueológicos como Los Amarillos (Quebrada de Humahuaca, Jujuy, Argentina) y Tastil (Salta, Argentina). En el primero de ellos, sobre una plataforma artificial construida frente a la plaza principal, se encontraron entierros directos 


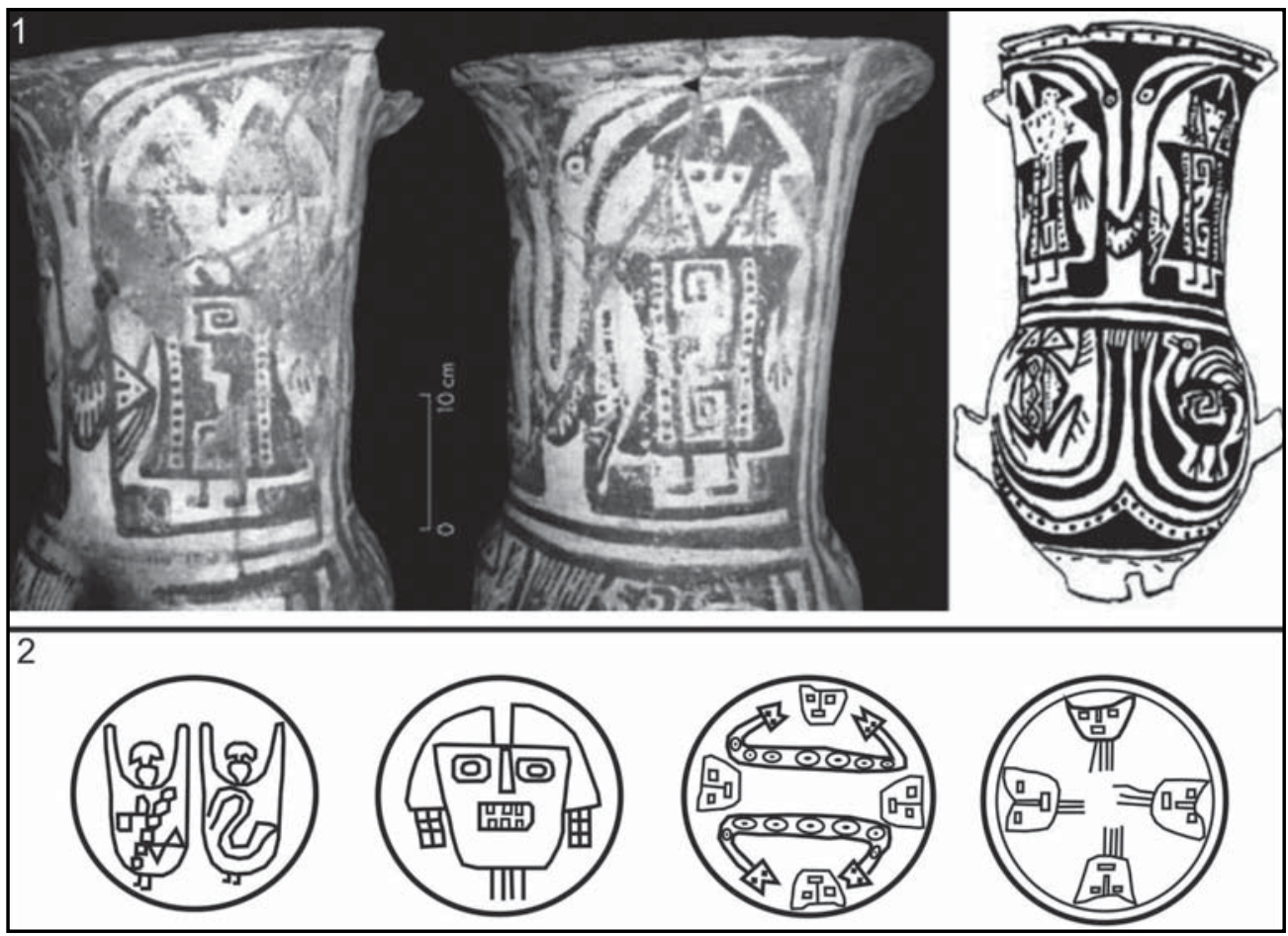

Figura 8: Objetos pertenecientes a la cultura Tardía Santa María donde se representan cabezas cercenadas: (1) representación de cabezas trofeo en las mejillas de la urna, tomado de Nastri 2008; (2) dibujo de discos de bronce, tomado de Nielsen 2007.

de partes de esqueletos humanos en asociación con tres sepulcros sobreelevados análogos a chullpas (Nielsen 2007). En el segundo sitio, el 75\% de los esqueletos adultos recuperados en las 140 tumbas excavadas por Cigliano (1973) carecían de cráneo, incluyendo los paquetes funerarios hallados junto con numerosos objetos dentro de un sepulcro sobreelevado encontrado en la plaza central del sitio. Nielsen (2007) manifiesta que en estos casos podría estar hablándose de cráneos trofeo que representan a ancestros y son venerados como tales.

\section{Discusión}

Los especialistas en religión andina coinciden en que el acto del sacrificio y la separación de la cabeza del cuerpo del individuo sacrificado están en estrecha relación con una economía de subsistencia agrícola-ganadera, la cual a su vez propicia un desarrollo social que lleva a un grupo cultural a centralizar el poder religioso en manos de unos pocos, y que se manifiesta en la construcción de una infraestructura arquitectónica y de artefactos varios dedicados exclusivamente a la actividad ritual (González 1998; Swenson 2003). 
Sin embargo, en la región del NOA, el acto de extraer el cráneo de un individuo junto con el trato diferencial dado a cada parte (cráneo por un lado y cuerpo por el otro) ya se practicaba en tiempos arcaicos, como lo demuestran los hallazgos realizados en la región puneña (Hernández Llosas 2000; López y Miranda 2007; Yacobaccio 2000, 2001). Es decir que, esta costumbre proviene de tiempos anteriores al Formativo, y posiblemente sufre una transformación en su significado y fin último, al igual que sucede en el Período Tardío, donde el significado religioso de los cráneos pasa a ocupar un segundo plano, para ser tratados como objetos de prestigio social producto de conflictos interétnicos (Nielsen 2007).

En síntesis, el uso y significado de los cráneos trofeo en el territorio del NOA fue cambiando con el paso del tiempo y el contexto socio-cultural en el cual se insertaban, siendo este hecho extensivo y ya conocido para culturas de los Andes centrales (Browne, Silverman y García 1993; Proulx 1999).

En los sitios Condorhuasi-Alamito se vislumbra el comienzo de una complejización social producto de una actividad religiosa separada del contexto doméstico; cada sitio presenta una infraestructura arquitectónica que muestra la importancia brindada a la actividad ceremonial (Condorhuasi-Alamito en Campo del Pucará) que se encuentra geográficamente separada de los sitios habitacionales (Tartusi y Núñez Regueiro 2001) (posiblemente Condorhuasi en el valle de Hualfín). Sin embargo, no es posible hablar de una separación marcada entre las esferas de lo sagrado y lo profano o doméstico. Según Insoll (2004) la dicotomía inherente entre lo evidentemente profano y lo sagrado es una creación reciente. En las culturas antiguas esta división no estaba tan claramente representada, y por lo general ambas esferas se complementaban y en muchos casos se superponían; los sitios aquí estudiados no parecen ser la excepción.

Tartusi y Núñez Regueiro (1993) plantean la existencia de una marcada diferencia entre el espacio sagrado y el doméstico o profano en estos sitios. El primero de estos espacios estaría constituido por las estructuras definidas como cobertizos, talleres metalúrgicos, montículo, plataformas y el patio central, mientras que los recintos B (o habitacionales) definirían el espacio doméstico o profano en el cual se realizarían todas las actividades domésticas rutinarias y se enterrarían a los muertos (era costumbre entre los pueblos formativos del NOA el enterrar a sus difuntos dentro de los estructuras que habitaban). Sin embargo, la presencia de entierros de adultos e infantes en estructuras supuestamente sagradas como los talleres metalúrgicos o cobertizos (sitios B-0, C-0, D-1, descritos en Núñez Regueiro 1998) y restos materiales que parecen indicar que en estos recintos se realizaban tanto tareas cotidianas (manos de mortero, diferentes tipos de recipientes de cerámica, morteros, semillas, un núcleo de obsidiana y restos de talla, etc.) como ceremoniales (Núñez Regueiro 1998), junto con dos entierros de infantes en las proximidades de una plataforma (sitio G-0 descrito en Núñez Regueiro 1998), nos hacen suponer que ésta dicotomía no era tan marcada ni evidente.

Paralelamente, estos sitios constituyen, hasta el momento, un caso único en la arqueología del NOA en lo que respecta a la disposición y construcción de sus estructuras. La información obtenida por los investigadores que los prospectaron y exca- 
varon, muestra que los mismos cumplían una función muy particular y hasta podría decirse que específica. La actividad ritual parece haber sido una de sus principales funciones, evidenciada en la presencia de estructuras dedicadas a ello (plataformas, montículo y patio central) y de una gran cantidad de objetos únicos en su tipo (suplicantes, hachas de cobre y de piedra, cabezas de piedra, cráneos trofeo, etc.) que probablemente tomaban parte en estas ceremonias (Tartusi y Núñez Regueiro 1993).

Dentro de estos rituales puede incluirse la práctica de sacrificios humanos y de animales, y la utilización de sus partes como objetos de culto. Es muy probable que, como ocurrió en otras culturas andinas (Verano 2008), el sacrificio humano no haya sido un acto frecuente, justificado en la cantidad de restos de individuos encontrados que parecen haber sido sacrificados. De un total de ocho sitios excavados y de la exhumación de 50 cuerpos, sólo en dos de los sitios (SCatAnd 1 B y SCatAnd $1 \mathrm{H}$ ) se encontró evidencia de este acto, y únicamente en el primero se encontraron pruebas de que se realizara el acto propiamente dicho, mientras que sólo 10 individuos parecen haber formado parte de estos actos como objetos de sacrificio. Ahora bien, la falta de dataciones absolutas, excavaciones y la pérdida de información de campo y gran cantidad de la muestra ósea (Roldán, Sampietro y Núñez-Regueiro 2009) no permite precisar la afirmación anterior, pero se debe de considerar que estos sitios estuvieron habitados durante más de 200 años.

El contexto arqueológico en el cual se encontraron algunos de los restos óseos humanos, indica la práctica de dos actividades que involucran, por un lado, el desmembramiento de cuerpos, y por el otro, la reutilización de sus partes como objetos con un contenido simbólico diferente al que poseían cuando formaban parte del individuo. El hallazgo de fragmentos de huesos desarticulados en los montículos y sobre el piso de ocupación de los sitios (incluyendo partes de cráneos), así como la presencia de una tibia humana trasformada en aerófono, el descubrimiento de un entierro donde se encontró parte de un individuo, desde la tercera vértebra lumbar hacia abajo (descritos en Núñez Regueiro 1998), y 5 cráneos bien conservados, son indicadores de lo anteriormente planteado.

Los cinco cráneos encontrados sobre el piso de ocupación en el sitio SCatAnd $1 \mathrm{H}$, cerca de una de las plataformas, fueron sometidos a una serie de modificaciones que incluyeron: el descarne, probablemente, poco después de la muerte del individuo ya que las marcas de cortes en la superficie de sus huesos muestran que los tejidos aún estaban frescos (Acreche 2001), la ampliación del foramen magnum para la extracción de las partes blandas y así lograr una mejor conservación, el cuidado de no exponerlos a la intemperie y su posible inhumación en conjunto (Figura 10). Todo ello sería indicativo de un tratamiento especial de estas cabezas, propio de los conocidos en el resto del territorio andino como «cráneos o cabezas trofeo».

En este punto es evidente que estos cráneos fueron producto de la actividad ritual, posiblemente de dos tipos o momentos ceremoniales diferentes. En el primero, el individuo es sacrificado y su cabeza cercenada y, en el segundo, el cráneo se transforma en un objeto sagrado utilizado en rituales de regeneración o asociados a la actividad agrícola. Consecuentemente, cuando la vida útil de estos objetos de culto culmina, se realiza su descarte enterrándolos en lugares especiales. Los basureros 
o montículos ceremoniales parecen haber cumplido con esta función. Los datos de las excavaciones refieren que los cráneos trofeo fueron encontrados sobre el piso de ocupación, es decir que, aún no habían sido descartados. A pesar de ello la cantidad de restos óseos humanos encontrados en los montículos, un cráneo casi completo cuyo foramen magnum fue ampliado y parte de otro cráneo, junto con otros restos arqueológicos, como fragmentos de huesos de camélidos, y de objetos de cerámica, metal, desechos líticos, espículas de carbón vegetal, etc. (descrito en Núñez Regueiro 1998), prueban que estos depósitos fueron utilizados para el descarte final de aquellos objetos rituales ya obsoletos.

No es posible precisar la situación en la que se obtuvieron estos cráneos. Los datos recogidos hasta el momento no permiten especificar si son producto de la actividad ritual, de actos de guerra o ambos. Sin embargo, es significativo el hecho de que los individuos a los cuales pertenecían murieron violentamente, producto de un golpe en el cráneo con un instrumento cortante (probablemente un hacha de metal similar a la hallada en uno de estos sitios) que en tres de ellos provocó fracturas que comprometieron ambas tablas del diploe, que en uno fracturó solamente la tabla interna del diploe no visible a simple vista por efecto de contra golpe, y que en el último provocó un defecto textural de la tabla externa que no comprometió la tabla interna del diploe (Figura 9).

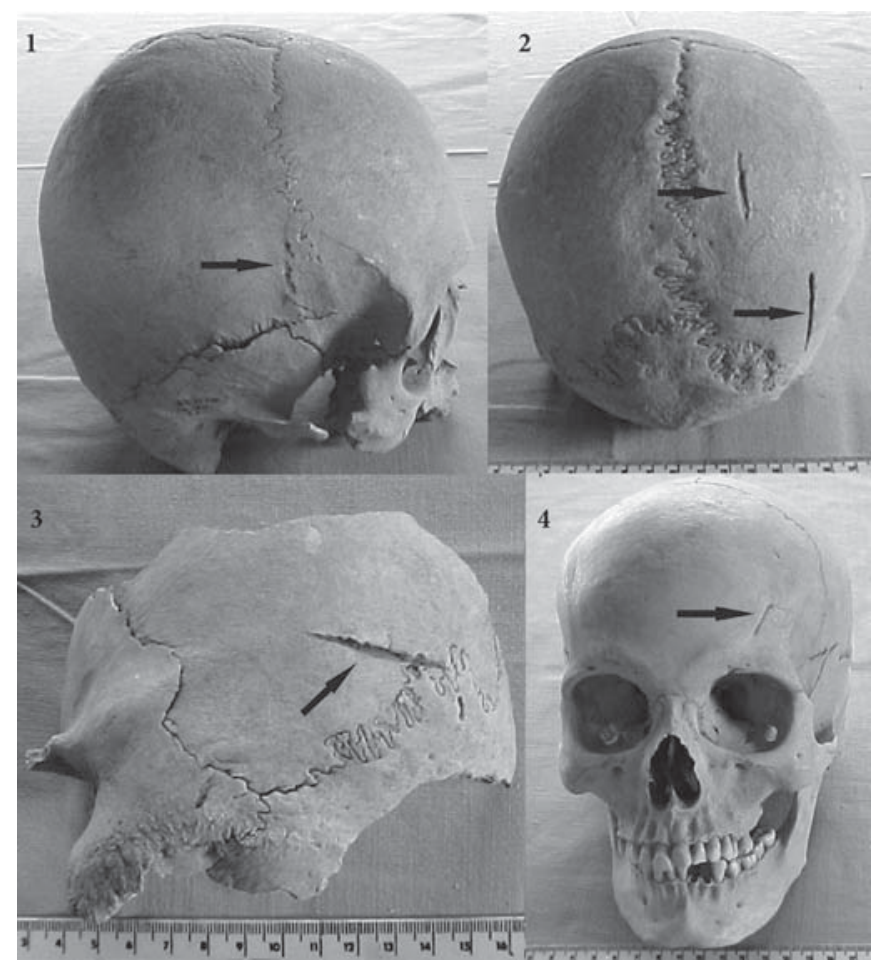

Figura 9: Fotografías de cuatro de los cinco cráneos trofeo encontrados en Campo del Pucará (Catamarca, Argentina) con marcas visibles de fracturas provocadas por un objeto filoso que fueron la causa de muerte. Las flechas negras señaladas el lugar donde se encuentran dichas lesiones. 
Si bien están representados ambos sexos - dos son masculinos y tres femeninos (Acreche 2001)-, tienen una serie de características en común, como por ejemplo se encuentran en un rango etario que va de $\operatorname{los} 25$ a los 45 años, es decir: son adultos; aparentemente pertenecieron a individuos provenientes de una población diferente a la que ocupó los sitios Condorhuasi-Alamito (Acreche 2001); el desarrollo de las celdillas mastoideas informa sobre el buen estado de salud del cual gozaban (Figura 10); y los cráneos masculinos presentaban lesiones circulares en diferentes partes de la calota con signos de curación (Figura 11).

Por lo tanto, podría hablarse de una selección de individuos para la decapitación y obtención de cráneos que luego serían transformados en «cráneos trofeo». Los signos de violencia que presentan y su procedencia étnica descartan la posibilidad de que estos cráneos pertenezcan a antepasados y refuerza la idea de que fueron producto de actos ceremoniales, ya sea simulando actos de guerra o sólo como resultado de un acontecimiento que precisaba imperiosamente de este tipo de sacrificio, como por ejemplo malas cosechas o epidemias que ponían en riesgo la vida social de estos grupos.

Para los período Formativo y Medio no hay evidencia de guerras, interétnicas como sucede en el Tardío (Nielsen 2007), ya sea porque las mismas no existían o porque no eran lo suficientemente importantes como para dejar rastros de su presencia, por lo que sería arriesgado poner como fuente de recurso para la obtención de

Figura 10: Fotografías y tomografías computadas de dos cráneos trofeo encontrados en Campo del Pucará (Catamarca, Argentina). Las flechas blancas señalan las celdillas mastoideas bien desarrolladas. A su vez en ambas fotos se observa el foramen magnum ampliado. 1) La tomografía acompañada por la fotografía del mismo cráneo 2) Idem anterior.

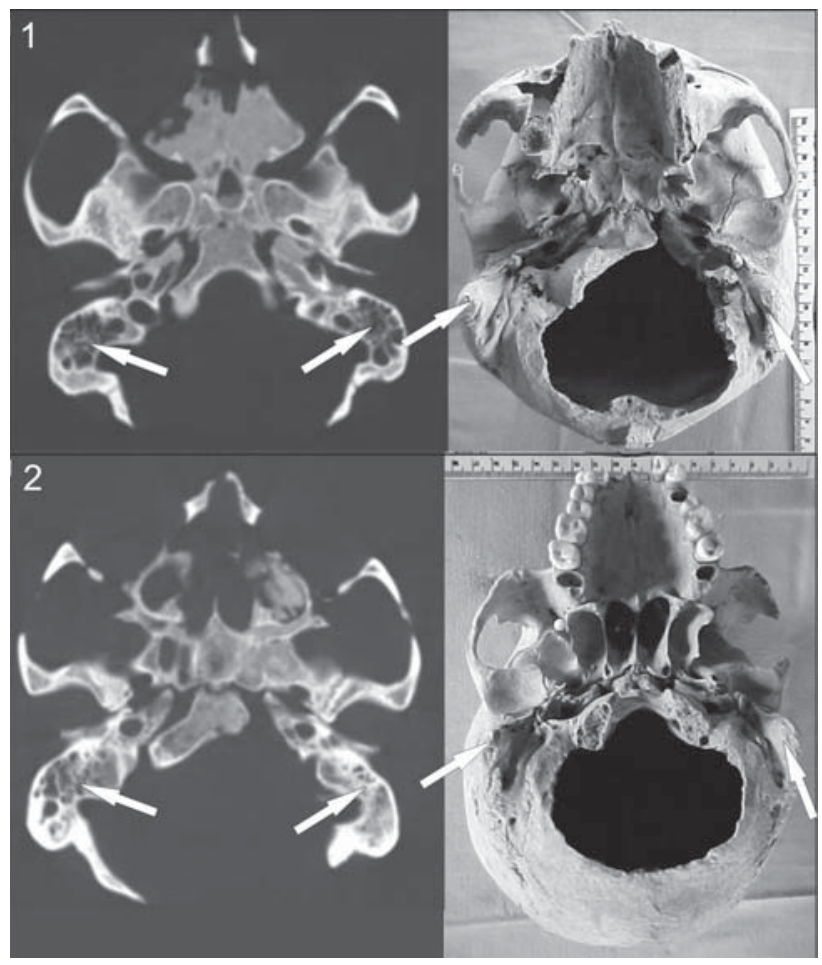




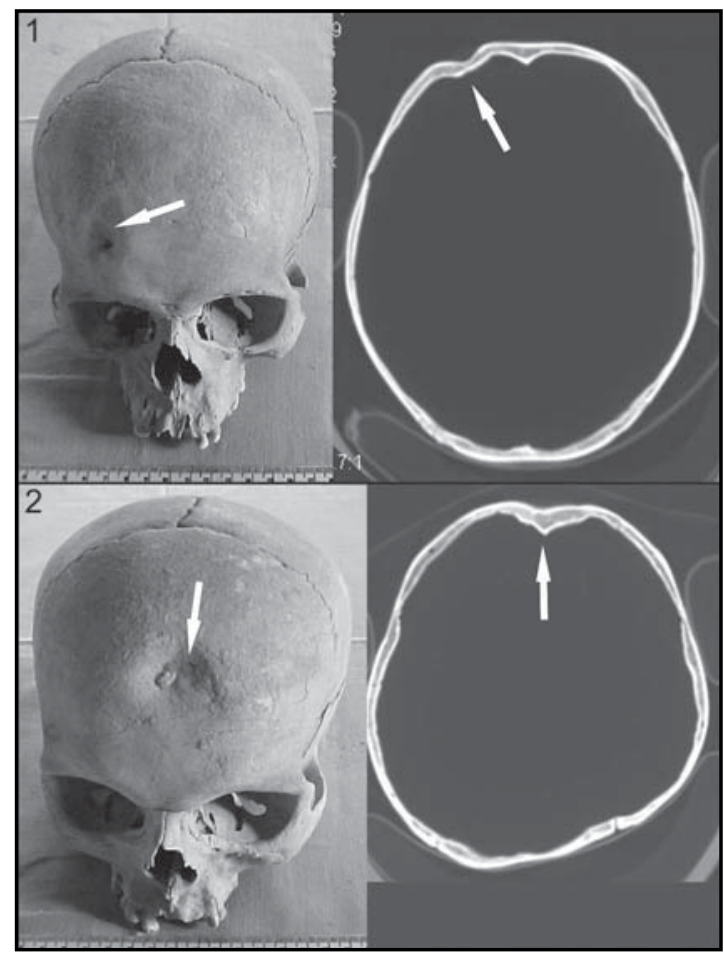

Figura 11: Fotografías y tomografías computadas de dos cráneos trofeo encontrados en Campo del Pucará (Catamarca, Argentina). Las flechas blancas señalan las lesiones circulares curadas. En las TAC puede observarse que estas lesiones comprometieron ambas tablas del diploe 1) La fotografía va acompañada por la tomografía del mismo cráneo 2) Idem anterior.

cráneos a este acto social en particular. Es más probable que se obtuvieran a partir de actividades ceremoniales específicas.

\section{Conclusiones}

Muchos de los datos consignados en este trabajo han sido mencionados por otros investigadores en trabajos anteriores, sin darle mayor profundidad al tema. Por lo tanto, el fin de este artículo fue integrar estos datos desde otra perspectiva y poder vislumbrar parte de la cosmovisión que compartían los pueblos formativos del NOA, como Condorhuasi-Alamito, con pueblos prehispánicos de otras regiones andinas.

En este contexto, retomando el objetivo de este trabajo, mostrar cómo se insertan los cráneos trofeos en el contexto ritual de los sitios ceremoniales de CondorhuasiAlamito, encontrados en Campo del Pucara (Catamarca, Argentina) y definir a su vez si forman parte de una concepción religiosa mayor, común a todos los pueblos andinos, consideramos que los actos sociales que llevan a la obtención final de los «cráneos trofeo» y su posterior utilización en otros actos ceremoniales junto con su descarte final, conllevaron una serie de momentos y significados religiosos que involucraron ceremonias diferentes, con fines distintos. En un principio, el sacrifico humano seguido de la decapitación y/o desmembramiento del cuerpo, continuando 
con el acondicionamiento del cráneo y su utilización como objeto suntuario en otros rituales y finalmente su posterior descarte.

Si bien la existencia de cabezas cercenadas ya se observa en tiempos pre-cerámicos, parece ser, que recién en el Período Formativo, con Condorhuasi-Alamito se vislumbra el comienzo de la obtención de cráneos trofeos para fines religiosos en centros especializados en dichos actos. Estas actividades continúan durante el Período Medio con Aguada, evidente en el contexto arqueológico observado en el sitio ceremonial de La Rinconada, donde la distribución de restos óseos humanos, salvando las diferencias arquitectónicas entre ambos lugares, muestran una conducta similar a la observada en los sitios de Campo del Pucará, y en la rica iconografía representada en distintos objetos. Para el Período Tardío se observa una ruptura socio-política con los períodos anteriores, lo cual se ve reflejado en sus actividades religiosas; las cabezas trofeo son representadas en la iconografía de la cultura Santa María asociadas a actividades bélicas, es decir, que su significado parece haber cambiado.

Puede enumerarse una serie de similitudes entre culturas del NOA con culturas de los Andes centro-sur, como por ejemplo diferentes momentos y actos rituales que llevan a la obtención final de cabezas o cráneos trofeo, es decir, que ello no ocurría de una sola vez; la transformación de estos cráneos y otras partes del cuerpo en objetos sagrados o simplemente en objetos que cumplen funciones distintas a las originarias; su descarte final en lugares sagrados ya sea basureros o acompañando a individuos inhumados, en grupo o aislados; el significado y las fuentes de obtención de estos cráneos que cambian con el paso del tiempo, situación que estuvo íntimamente relacionada con las condiciones socio-económica vividas en cada momento por cada cultura.

El registro arqueológico muestra que no sólo características como los cráneos trofeo fueron compartidas entre estas culturas, sino que hay otros componentes o rasgos religiosos que acompañan a dichos cráneos.

\section{Referencias bibliográficas}

ACRECHE, Noemí

2001 «Los cráneos trofeo en Campo del Pucará», en Actas del XIII Congreso Nacional de Arqueología Argentina, pp. 87-93. Córdoba.

Browne, David M., Helaine Silverman y Rubén García

1993 «A Cache of 48 Nasca Trophy Heads from Cerro Carapo, Perú». Latin American Antiquity 4 (3): 279-294.

Cigliano, Eduardo M.

1973 Tastil, una ciudad preincaica argentina. Buenos Aires: Ediciones Cabargon.

De LeONARDis, Lisa

2000 «The Body Context: Interpreting Early Nasca Decapitated Burials». Latin American Antiquity 11 (4): 363-386.

DeMarrais, Elizabeth, Luis J. Castillo y Timothy Earle

1996 «Ideology, Materialization, and Power Strategies». Current Anthropology 37 (1): $15-31$. 
ELIADE, Mircea

1964 Tratado de Historia de las Religiones. México: Era.

GonzÁLEz, Alberto R.

1979 «Pre-Columbian metallurgy of Northwest Argentina: Historical development and cultural process», en Precolumbian Metallurgy of South America, E. Benson, ed., pp. 133-202. Washington: Dumbarton Oaks.

1998 Cultura La Aguada. Buenos Aires: Filmediciones Valero.

2004 «La Arqueología del Noroeste Argentino y las culturas Formativas de la Cuenca del Titicaca». Relaciones de la Sociedad Argentina de Antropología 29: 7-37.

GonzÁlez, Alberto R. y M. I. BALDINI

1989 «Vaquerías: la más antigua cerámica polícroma del Noroeste Argentino». ARTINF 14: 9-12.

Gordillo, Inés y Ana SolARI

2009 «Prácticas mortuorias entre las poblaciones Aguada del valle de Ambato (Catamarca, Argentina)». Revista Española de Antropología Americana 39 (1): 31-51.

Hernández Llosas, M. Isabel

2000 «Quebradas altas de Humahuaca a través del tiempo: el caso de Pintoscayoc». Estudios Sociales del NOA 2: 167-224.

HiLl, Erica

2003 «Sacrificing Moche Bodies». Journal of Material Culture 8 (3): 285-299.

Insoll, Timothy

2004 Archaeology, Ritual, Religion. Londres: Routledge.

López, Gabriel E. J. y Paula C. Miranda

2007-08 «El 'muerto' del salar: descripción de un hallazgo bioarqueológico a cielo abierto datado en ca. 3700 AP en el borde del salar de Pastos Grandes, Puna de Salta». Arqueología 14: 199-215. Buenos Aires.

LuPo, Liliana C.

1998 Estudio sobre la lluvia polínica actual y la evolución del paisaje a través de la vegetación durante el Holoceno en la cuenca del río Yavi. Borde oriental de la Puna, Noroeste argentino. Tesis doctoral. Bamberg: Universität Bamberg.

NASTRI, Javier

2008 «La figura de las largas cejas de la iconografía santamariana. Chamánismo, sacrificio y cosmovisión Calchaquí». Boletín del Museo Chileno de Arte Precolombino 13 (1): 9-34.

NiELSEN, Axel E.

1995 «Architectural Performance and the Reproduction of Social Power», en Expanding Archaeology, J. M. Skibo, W. H. Walker y A. E. Nielsen, eds., pp. 47-66. Salt Lake City: University of Utha Press.

2007 «Armas significantes: tramas culturales, guerra y cambio social en el sur andino prehispánico». Boletín del Museo Chileno de Arte Precolombino 12 (1): 9-41. 
Nielsen, Axel E. y William H. Walker

1999 «Conquista ritual y dominación política en el Tawantinsuyu: El caso de Los Amarillos (Jujuy, Argentina)», en Teoría Social en la Arqueología Latinoamericana Contemporánea, A. Zarankin y F. Acutto, eds., pp. 153-169. Buenos Aires: Ediciones del Tridente.

NúÑEz RegueIRo, Víctor A.

1998 Arqueología, Historia y Antropología de los sitios de Alamito. San Miguel de Tucumán: Ediciones INTERDEA.

NúÑez Regueiro, Víctor A. y Marta TARTusi

2002 «Aguada y el proceso de integración regional». Estudios Atacameños 24: 9-19.

Pérez Gollán, José A.

2000 «El jaguar en llamas (la religión en el antiguo Noroeste Argentino)», en Nueva Historia Argentina. Los pueblos originarios y la conquista, vol. 1, M. N. Tarragó, ed., pp. 229-257. Buenos Aires: Editorial Sudamericana.

Proulx, Donald A.

1999 «Nasca Headhunting and the Ritual Use of Trophy Heads», en Nasca: Geheimnisvolle Zeichen om Alten Peru, J. Rickenbach, ed., pp. 79-87. Zürich: Museum Rietberg.

2001 «Ritual Uses of Trophy Heads in Ancient Nasca Society», en Ritual Sacrifice in Ancient Peru, E. Benson y A. Cook, eds., pp, 119-136. Austin: University of Texas Press.

RAPPAPORT, ROY A.

1971 «The Obvious Aspects of Ritual», en Ecology, Meaning and Religion, pp 427-440. Richmond: North Atlantic Books.

Roldán, Jimena; M. Marta Sampietro Vattuone y Víctor A. NúÑez Regueiro

2009 «Tras 50 años de bioantropología en Campo del Pucará (Catamarca, Argentina)». Revista Española de Antropología Americana 39 (2): 17-39.

SAmpietro Vattuone, M. Marta

2002 Contribución al conocimiento geoarqueológicos del valle de Tafí, Tucumán (Argentina). Tesis doctoral. Universidad Nacional de Tucumán.

Sampietro Vattuone, M. Marta; Jimena Roldán y Carlos E. RoldÁn

2004 «Cráneos Trofeo de Campo del Pucará (Catamarca, Argentina)», en Actas de Resúmenes, XXI Jornadas Cientificas de la Sociedad de Biología de Tucumán, pág. 123.

Swenson, Edward R.

2003 «Cities of violence. Sacrifice, power and urbanization in the Andes». Journal of Social Archaeology 3 (2): 256-296.

TARTUSi, Marta y Víctor A. NúÑEz RegueIro

1993 Los centros ceremoniales del NOA. Publicaciones $n^{\circ}$ 5, Serie Ensayo $n^{\circ} 1$. San Miguel de Tucumán: Instituto de Arqueología, Universidad Nacional de Tucumán.

2001 «Fenómenos cúlticos tempranos en la subregión valliserrana», en Historia Argentina Prehispánica, Eduardo E. Berberián y Axel Nielsen, eds., vol. 1, pp. 127-165. Buenos Aires: Brujas. 
Thompson, Lonnie G.; Ellen Moseley-Thompson; John F. Bolzan y B. R. Koci

1985 «A 1500-year Record of Tropical Precipitation in Ice Cores from the Quelcaya Ice Cap, Peru». Science 229: 971-973.

VERANO, John W.

1995 «Where do they rest? The treatment of human offerings and trophies in ancient Peru», en Tombs for the Living: Andean Mortuary Practices, T. Dillehay, ed., pp. 189-227. Washington: Dumbarton Oaks.

2008 «Trophy Head-Taking and Human Sacrifice in Andean South», en Handbook of South American Archeology, Helaine Silverman y William H. Isbell, eds., pp. 1047-1060. Nueva York: Springer.

VignATI, Milciades A.

1930 «Los cráneos-trofeo de las sepulturas indígenas de la Quebrada de Humahuaca (Provincia de Jujuy)». Archivos del Museo Etnográfico 1. Buenos Aires.

WALKER, William H.

1995 «Ceremonial Trash? », en Expanding Archaeology, J. M. Skibo, W. H. Walker y A. E. Nielsen, eds., pp. 67-79. Salt Lake City: University of Utah Press.

1998 «Where are the Witches of Prehistory?». Journal of Archaeological Method and Theory 5: 245-308.

WALKer, William H. y Lisa J. LuCERo

2000 «The depositional history of ritual and power», en Agency in Archaeology, M. Dobres y J. Robb, eds., pp. 130-147. Londres: Routledge.

YacoBaccio, Hugo

2000 «Inhumación de una cabeza aislada en la Puna Argentina». Estudios Sociales del NOA 2: 59-71.

2001 «Cazadores complejos y domesticación de camélidos», en El uso de los camélidos a través del tiempo, G. Mengoni Goñalons, D. Olivera y H. Yacobaccio, eds., pp. 261-282. Buenos Aires: Ediciones del Tridente. 